\title{
Revisão sistemática de literatura sobre a Psicopatologia Fenomenológica no Brasil
}

Systematic review of literature on the Phenomenological Psychopathology in Brazil

\author{
Clarissa Garcia Jaborandy de Mattos Dourado ${ }^{1}$ \\ Virginia Moreira $^{2}$ \\ Anna Karynne da Silva Melo ${ }^{3}$
}

\section{Resumo}

A psicopatologia fenomenológica teve seu início nos anos 1920, apresentando uma nova maneira de compreender os transtornos psicopatológicos. Este artigo teve como objetivo analisar o panorama da psicopatologia fenomenológica nos periódicos brasileiros. Foi realizada uma revisão sistemática de literatura qualitativa nas bases de dados SciELO, PePSIC, BVS e Portal de Periódicos CAPES. Foram encontrados 347 artigos, dos quais 59 foram analisados. Destes, 45 foram artigos teóricos e 14 foram estudos sobre a prática clínica. Foi possível constatar que, em um intervalo de 12 anos, a quantidade de publicações nessa área de conhecimento em periódicos brasileiros ainda é pequena, principalmente no que concerne às publicações de pesquisas sobre a prática clínica, representando uma lacuna na área. A psicopatologia fenomenológica se apresenta como um campo com muitas alternativas, mas, também, com muitos desafios e intenso trabalho a ser realizado.

Palavras-chave: Psicopatologia Fenomenológica; Revisão Sistemática da Literatura; Pesquisas em Psicopatologia Fenomenológica

\begin{abstract}
The phenomenological psychopathology has its beginning in the 1920s, showing a new way to understand the psychopathological disorders. This article aims to analyze the panorama of the phenomenological psychopathology in Brazilian journals. It was held as a systematic review of qualitative literature in databases such as SciELO, PePSIC, BVS and CAPES Journals Portal. 347 articles were found, of which 59 were analyzed. 45 out of those, were theoretical articles and 14 were studies on clinical practice. It was found that, in a range of twelve years, the number of publications in this field of knowledge in Brazilian journals is still small, especially regarding publications on clinical practice
\end{abstract}


research, representing a gap in the area. The phenomenological psychopathology appears as a field with many alternatives, but also with many challenges and work to be done.

Keywords: Phenomenological Psychopathology; Systematic Literature Review; Research in Phenomenological Psychopathology

\footnotetext{
${ }^{1}$ Instituto de Psicologia Humanista e Fenomenológica do Ceará, Universidade de Fortaleza UNIFOR - Fortaleza (CE), Brasil. E-mail: clarissa_garcia@ hotmail.com

${ }^{2}$ Universidade de Fortaleza - UNIFOR - Fortaleza (CE), Brasil. E-mail: virginiamoreira@ unifor.br

${ }^{3}$ Universidade de Fortaleza - UNIFOR - Fortaleza (CE), Brasil. E-mail: karynnemelo@unifor.br
}

Este artigo está vinculado ao projeto de produtividade em pesquisa PQ-2 - CNPq: Fenomenologia Clínica como Intervenção Terapêutica. Financiamento Edital 05/2016 Financiamento Complementar à Pesquisa, Universidade de Fortaleza - UNIFOR - projeto 1965 e ao projeto Saúde Mental, Psicologia e Fenomenologia: compreendendo a interlocução entre os campos de saber. Financiamento Edital 06/2016 Auxílio à pesquisa Jovens Pesquisadores, Universidade de Fortaleza - UNIFOR projeto 2028.

Financiamento: Fundação Cearense de Apoio Científico e Tecnológico (FUNCAP).

Recebido em: 11/8/2016

Aceito em: 27/10/2016 


\section{Introdução}

O percurso histórico da psicopatologia fenomenológica contemporânea ocorreu de maneira gradual, em movimentos de aproximação e de distanciamento entre áreas do conhecimento, como a psiquiatria, a psicologia e a filosofia, mas, em grande parte, pautado no desenvolvimento da psiquiatria, que se sustentava, segundo Schneider (2009), no modelo de clínica médica vigente no início do século XX, no qual se valorizava uma lógica classificatória de natureza empirista.

A psicopatologia fenomenológica teve seu marco inicial no dia 25 de novembro de 1922, quando, na $63^{\text {a }}$ sessão da Sociedade Suíça de Psiquiatria de Zurique, Ludwig Binswanger apresentou um trabalho intitulado La Phenomenologie e Eugène Minkowski, um estudo de caso sobre melancolia esquizofrênica (Tatossian, 1979/2006). Essa nova maneira de se aproximar dos transtornos mentais e psicológicos recebeu, segundo Charbonneau (2010), diversas denominações: “fenomenologia psiquiátrica, fenomenologia clínica, análise fenômeno-estrutural, análise existencial, Daseinsanalyse, ou antropologia fenomenológica das psicoses" (p. 12).

Considerando que, no contexto da psicopatologia fenomenológica, há diferentes nomenclaturas e perspectivas, nos questionamos sobre as produções nessa área, quais tipos de pesquisas adotaram a psicopatologia fenomenológica como referência teórica, de que concepções partiram e como tem sido discutida nas produções científicas. Posto isso, este artigo teve como objetivo analisar o panorama da psicopatologia fenomenológica nos periódicos brasileiros.

\section{Métodos}

A revisão sistemática da literatura (RSL) consiste em “[...] uma revisão de estudos por meio de uma abordagem sistemática, utilizando metodologia claramente definida, buscando minimizar os erros nas conclusões [...]. A revisão sistemática é, portanto, uma forma de se apropriar das melhores evidências externas [...]" (Pereira \& Bachion, 2006, p. 492), pois sintetiza as evidências científicas disponíveis na literatura (De-la-Torre-UgarteGanilo, Takahashi \& Bertolozzi, 2011), identificando, dentre os estudos encontrados, aqueles que apresentaram maior qualidade metodológica (Berwanger, Suzumura, Buehler \& Oliveira, 2007; Pereira \& Bachion, 2006), evitando vieses e tornando possível uma análise mais objetiva dos dados obtidos (Sampaio \& Mancini, 2007). Nesta pesquisa, realizamos uma RSL de caráter qualitativo, o que permitiu entender e interpretar as 
questões propostas a partir dos dados coletados, podendo subsidiar a elaboração de novos aportes teóricos (De-la-Torre-Ugarte-Guanilo, Takahashi \& Bertolozzi, 2011).

Utilizamos como base de dados o Portal de Periódicos CAPES, o SciELO, o PePSIC e a Biblioteca Virtual em Saúde (BVS). As buscas foram realizadas a partir do termo "Psicopatologia fenomenológica" e das palavras-chave "psicopatologia"; "fenomenologia"; "existencial" e "pesquisa". Inicialmente, buscamos somente a partir do termo "psicopatologia fenomenológica". Posteriormente, recorremos à estratégia de busca combinando o termo e as palavras-chave, para possibilitar maior número de resultados, configurando a pesquisa da seguinte forma: "psicopatologia fenomenológica" AND pesquisa; "psicopatologia fenomenológica" AND existencial; psicopatologia AND fenomenologia e psicopatologia AND existencial. À palavra "existencial” foi acrescentado um asterisco, no caso do Portal de Periódicos CAPES e BVS, ou um cifrão, nas bases SciELO e PePSIC. Este recurso ajuda na ampliação da busca, pois busca palavras com a mesma raiz. No caso de "existencial", poderiam ser recuperados, por exemplo, os termos "existencialismo", "existencialista", etc.

Foram incluídos os artigos publicados em periódicos brasileiros, entre janeiro de 2004 e agosto de 2016, escritos em português, inglês, espanhol ou francês e que estivessem disponíveis em texto completo. Foram considerados estudos teóricos e empíricos que contivessem no título, no resumo, ou nas palavras-chave o termo ou as palavras indicadas anteriormente. Foram excluídos os artigos publicados antes ou depois do intervalo de tempo determinado e aqueles que não disponibilizaram o texto completo e estavam publicados em periódicos de outros países. Também não foram considerados livros, resenhas, teses e dissertações.

Submetidos aos critérios de inclusão e exclusão, os artigos foram organizados levando em conta o ano das publicações, os periódicos nos quais haviam sido publicados, as temáticas desenvolvidas, sua perspectiva teórica e se eram trabalhos empíricos de campo, empíricos ou teóricos. Depois de agrupados com base nesses aspectos, foram estabelecidas categorias para realizar a etapa final de síntese e discussão dos resultados.

\section{Resultados e Discussão}

Após consultar as bases de dados descritas na metodologia, foi obtido um total de 347 artigos, subdivididos da seguinte forma: 135 artigos no Portal de Periódicos CAPES; 25 artigos no SciELO; 49 artigos no PePSIC e 138 artigos na BVS. Somados os resultados 
dos bancos de dados, foram localizados 59 trabalhos com o termo "Psicopatologia fenomenológica", 14 artigos resultantes da combinação "Psicopatologia fenomenológica" AND Existencial, 8 resultados com "Psicopatologia fenomenológica" AND Pesquisa, 141 artigos com Psicopatologia AND Fenomenologia e 125 artigos como resultado da combinação Psicopatologia AND Existencial.

Alguns artigos foram apresentados mais de uma vez na mesma ou em diferentes bases de dados, no decorrer das consultas. Com a eliminação dos duplicados, que totalizaram 183 artigos, os resultados obtidos foram reduzidos de 347 para 164 artigos. Após esta etapa, dentre os 164, 105 foram excluídos com base nos critérios de inclusão e exclusão, restando, portanto, 59 artigos a serem analisados (Figura 1, Anexo 1).

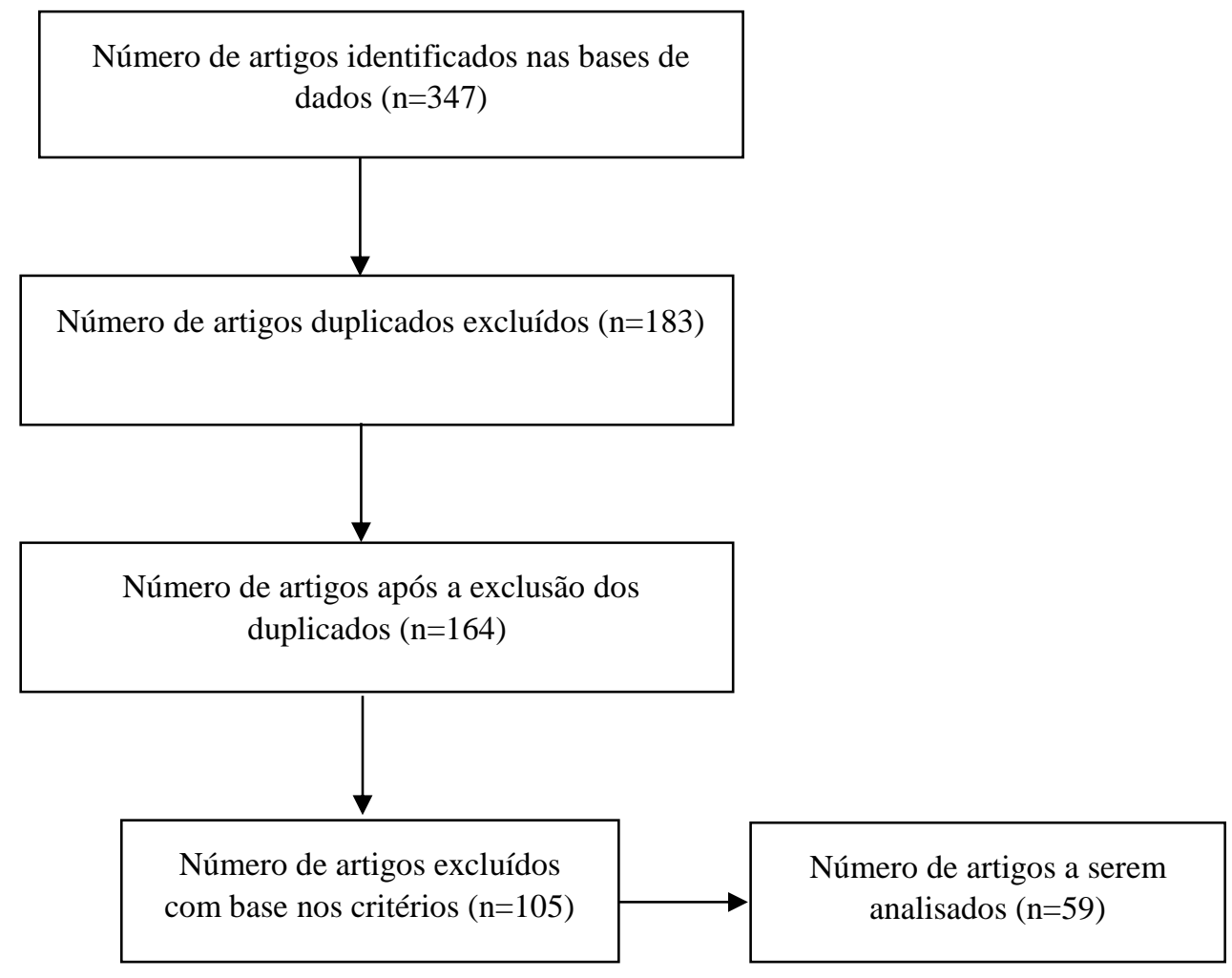

Figura 1. Fluxograma das etapas, com base na proposta de Moher, Liberati, Tetzlaff e Altman (2009)

No que concerne ao ano das publicações, dos 59 artigos incluídos, o ano de 2013 foi o período com maior número de publicações, totalizando 10 trabalhos, seguido pelos anos de 2009 e 2015, ambos com 9 artigos publicados. Os anos de 2004, 2006 e 2007 tiveram uma publicação cada um. No ano de 2005, houve 2 artigos publicados. Tanto em 2008, quanto em 2011, foram publicados 4 artigos e, em 2010, dois artigos. Nos anos de 
2012 e 2014 constam 5 publicações e, em 2016, 6 artigos publicados até o mês de agosto (Figura 2).

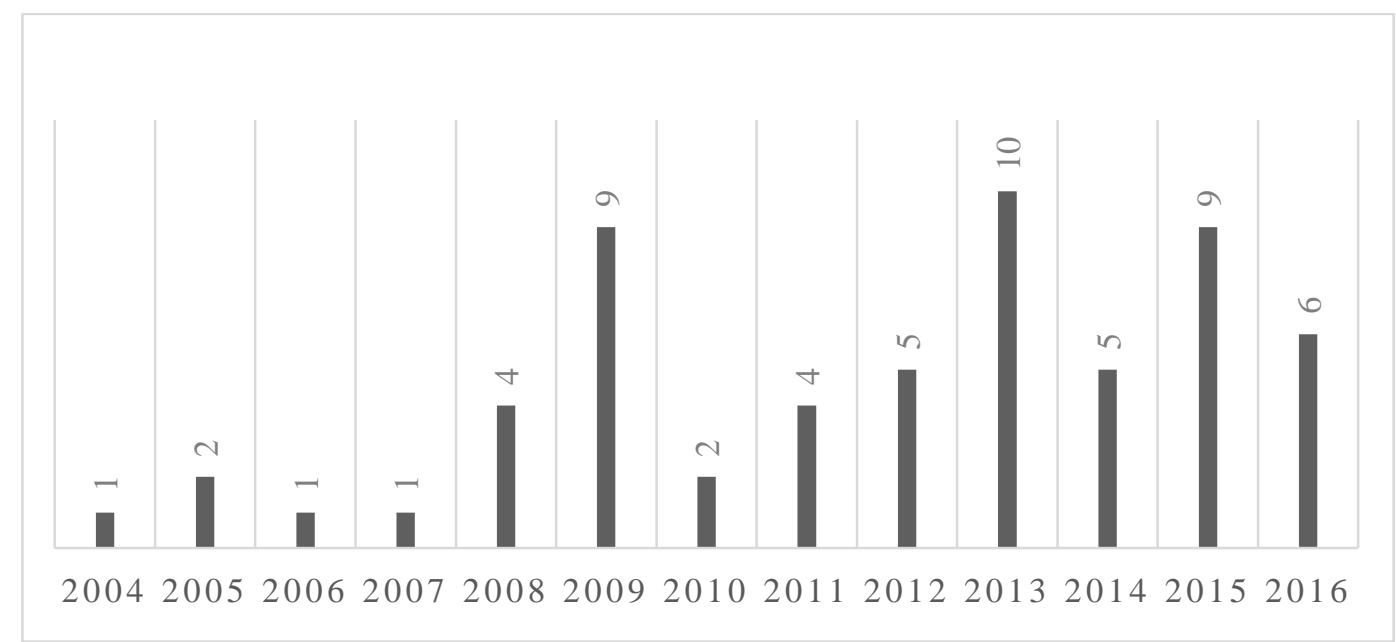

Figura 2. Número de artigos no período de 2004 a 2016 (n=59)

É interessante atentar para os periódicos nos quais esses artigos foram publicados, pois, desta forma é possível observar em quais áreas os trabalhos que utilizam a psicopatologia fenomenológica como referencial teórico, ou discutem assuntos relacionados a este tema, estão sendo divulgados. Nesta pesquisa, constatamos que, com exceção das revistas Interface - Comunicação, Saúde e Educação, Ágora, Ciência e Saúde Coletiva e Saúde e Sociedade, os demais periódicos são, primordialmente, direcionados para os trabalhos nos campos da psicologia, psiquiatria e psicopatologia.

Ainda em relação às revistas que editam e publicam os artigos, consideramos, também, o qualis correspondente a elas. De acordo com o site da Coordenação de Aperfeiçoamento de Pessoal de Nível Superior (CAPES), "qualis é o conjunto de procedimentos utilizados pela Capes para estratificação da qualidade da produção intelectual dos programas de pós-graduação" (CAPES, 2014, s/p).

A indicação da qualidade dos periódicos é atribuída da seguinte maneira: A1 é o nível mais elevado, seguido pelos níveis A2; B1; B2; B3; B4; B5 e C. Este último possui peso zero (CAPES, 2014). O mesmo periódico pode ter qualis diferente, dependendo da área no qual é avaliado. Para os periódicos selecionados, utilizou-se, como referência, o qualis da área da psicologia, de acordo com a classificação de 2014, última atualização divulgada. 
Os 59 artigos foram publicados em 22 periódicos com diferentes classificações e em dois sem qualis. As publicações se concentraram em 2 periódicos com qualis $\mathrm{B} 1$ e A2, respectivamente, na Revista da Abordagem Gestáltica, com 22 artigos, e na Revista Latinoamericana de Psicopatologia Fundamental, com 9 artigos publicados. Neste aspecto, os trabalhos sobre psicopatologia fenomenológica e áreas afins encontravam-se, em sua maioria, em revistas com boa qualificação. Dentre os artigos selecionados, 7 foram publicados em periódicos com qualis A1; 16 artigos em revistas com classificação A2; 28 publicações com qualis $\mathrm{B} 1 ; 4$ com qualis $\mathrm{B} 2$ e 2 artigos em periódico classificado como B3. Dois artigos foram publicados em periódicos que não possuem qualis (Figuras 3 e 4).

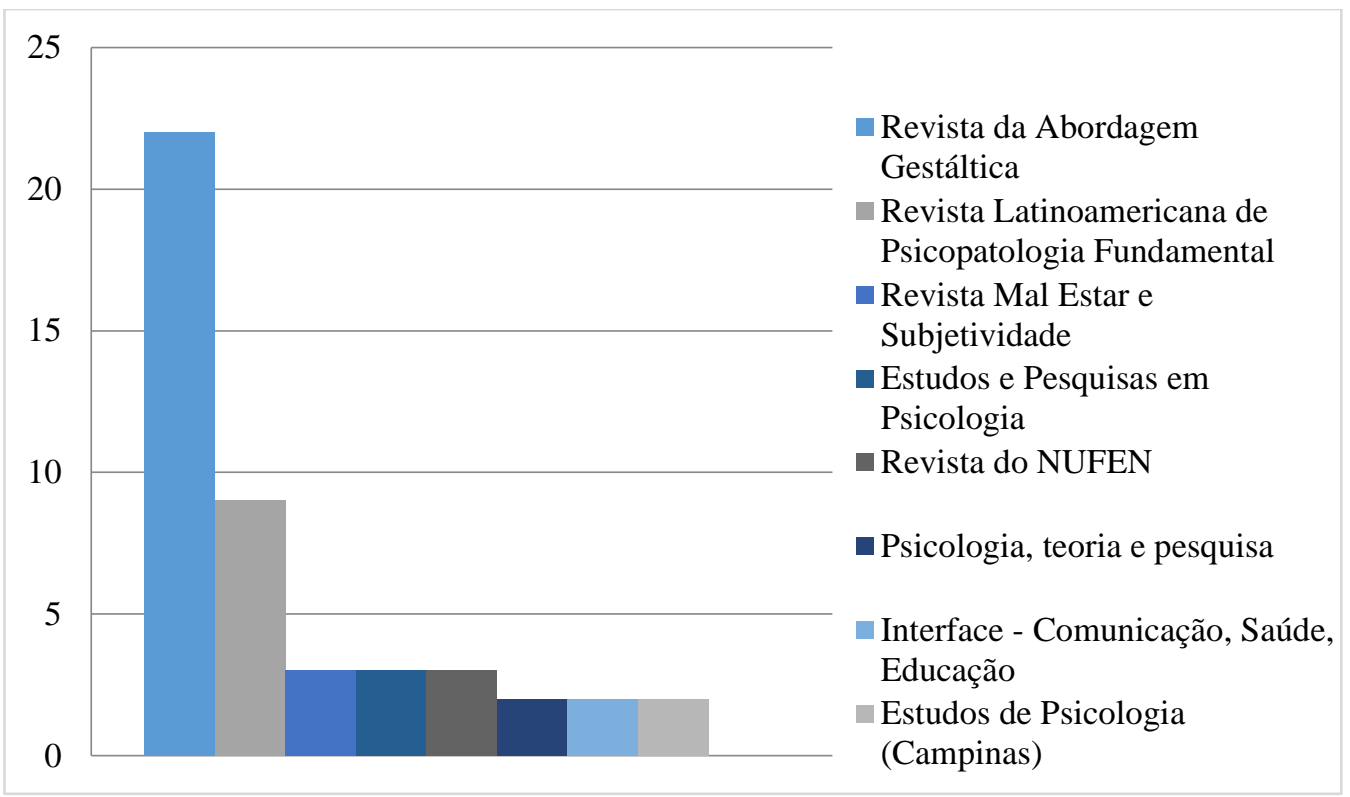

Figura 3. Número de artigos analisados distribuídos nos periódicos em que foram publicados

Na Figura 3, não estão incluídos os periódicos nos quais foi publicado apenas um artigo. São eles: Aletheia, Memorandum, Fractal, Psicologia em Estudo, Psicologia: Reflexão e Crítica, Revista Brasileira de Psiquiatria, Arquivos Brasileiros de Psicologia, Ágora, Psicologia Revista, Boletim de Psicologia, Ciência e Saúde Coletiva, Estudos de Psicologia (Natal), Saúde e Sociedade e Trends in Psychiatry and Psychotherapy.

Foram encontrados 45 trabalhos de natureza teórica e 14 estudos empíricos. Após a leitura destes, foram organizados em categorias, apresentadas a seguir. 


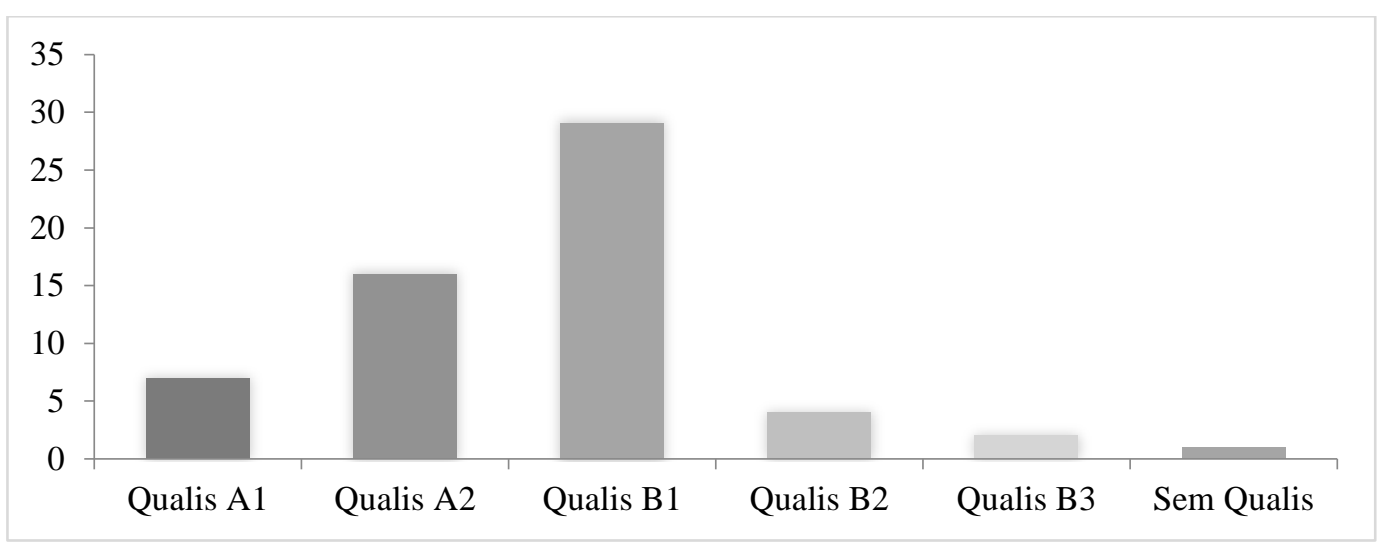

Figura 4. Divisão do número de artigos com base na classificação Qualis do periódico no qual foram publicados

Psicopatologia fenomenológica: articulações com as teorias psicológicas/psicoterápicas e as práticas em psicologia

Sob o olhar da clínica fenomenológica-existencial, partindo da Gestalt-Terapia (GT) e da Daseinsanalyse, Melo, Boris e Stoltenborg (2009) discutiram o caso clínico de uma paciente diagnosticada com transtorno de personalidade borderline, propondo uma interlocução entre a Gestalt-Terapia e a Daseinsanalyse, na medida em que ambas compreendem que "[...] a gênese dos processos psicopatológicos ocorre na construção do projeto de vida" (p. 135) e que os transtornos psicopatológicos consistem em uma cristalização que reduz as possibilidades de existência e potencialização da vida.

Aproximações entre a Abordagem Centrada na Pessoa (ACP) de Carl Rogers e a psicopatologia fenomenológica proposta por Arthur Tatossian foram feitas por Souza, Callou e Moreira (2013). Assim como Rogers, mas no campo da psiquiatria, Tatossian ressaltou, em sua proposta, a importância do trabalho direto com os pacientes, buscando se aproximar de suas formas de estar no mundo.

Os dois trabalhos apresentaram, em comum, a discussão sobre a maneira de compreender os transtornos psicopatológicos que são próprios da psicopatologia fenomenológica, articulando-a com uma teoria psicológica. A psicopatologia fenomenológica preza muito mais do que os sintomas, compreendendo os transtornos mentais em sua complexidade, considerando aspectos da história de vida do paciente, suas relações com o tempo e o espaço, pensando a subjetividade enquanto intersubjetividade e tendo como foco a compreensão das diferentes formas de ser-no-mundo.

O artigo de Guede, Monteiro-Leitner e Machado (2008) tomou como base a ACP e os pressupostos fenomenológicos-existenciais, ao apresentar um estudo de caso sobre um 
jovem adulto que chega à psicoterapia em um momento de crise, após o término de um relacionamento. $\mathrm{O}$ autor atribuiu ao psicoterapeuta, através de sua capacidade de escuta, a possibilidade de ajudar o cliente a reatualizar o seu projeto existencial, assemelhando-se, em certa medida, ao que Galli (2009) trabalhou em seu texto.

Fazendo referência à ontologia proposta por Heidegger, na obra Ser e Tempo, Galli (2009) articulou a GT com a compreensão fenomenológica das noções de saúde e doença, afirmando que "[...] a fenomenologia conduziu a uma pluralidade de pontos de vista em psicopatologia" (p. 60), sendo a psicopatologia descritiva proposta por Karl Jaspers e a Daseinsanalyse proposta por Binswanger os métodos mais conhecidos.

No que concerne à GT, a fenomenologia aparece como método, no esforço em descrever as experiências e observar o que ocorre no "aqui e agora", atento para a temporalidade, a espacialidade e as demais formas através das quais a pessoa se movimenta no mundo (Galli, 2009). Sob este aspecto, Antony (2009a; 2009b) e Tenório (2012) discutiram as psicopatologias como disfunções nas relações entre organismo/ambiente e concordaram com Galli (2009) a respeito da importância de olhar para as psicopatologias considerando o indivíduo em sua totalidade, levando em conta seu contexto.

A GT, em diálogo com as discussões feitas por Tatossian (1979/2006) sobre o modo de ser esquizofrênico, foi apresentada por Santos Filho e Costa (2016) a partir de trechos de sessões de psicoterapia de dois clientes. Ambas as perspectivas compreendem a esquizofrenia "como um modo de ser, um fenômeno relacionado a um contexto e que não pode ser visto simplesmente como uma doença, ou seja, algo individual” (p. 34).

Ampliando as discussões sobre as práticas em psicoterapia e sua relação com a psicopatologia fenomenológica e disciplinas afins, Antúnez e Safra (2014) buscaram compreender a psicopatologia por meio de um diálogo interdisciplinar entre a obra de Pablo Neruda, Michel Henry e Eugène Minkowski. Antúnez e Safra, afirmaram que o que há em comum entre o poeta, o filósofo e o psiquiatra é o interesse em "[...] ajudar a melhorar e compreender a condição humana" (p. 369).

Tal compreensão se aproxima da associação feita por Antúnez e Wondracek (2012) entre a fenomenologia de Michel Henry, a psicopatologia e a psicoterapia. Esta concepção retoma a noção de pathos, entendendo o sofrimento como parte integrante da vida, o movimento do ser enquanto "eu posso", cujas ações se dão na imediaticidade, e o corpo como dotado de sentidos. O trabalho clínico consiste, portanto, segundo os autores, na 
intersubjetividade, na compreensão do outro, respeitando seu modo de ser, distanciando-se das concepções psiquiátricas baseadas em evidências e aspectos observáveis.

O distanciamento de ações centradas apenas na doença e numa visão individualista do homem segue - a fim de evitar a estigmatização e discriminação - em direção à compreensão da alteridade e investimento nas potencialidades de desenvolvimento das pessoas com transtornos psicopatológicos. Silva e Cardoso (2013) discutiram, a partir do pensamento de Edith Stein, cujo trabalho foi inspirado na fenomenologia de Edmund Husserl, suas contribuições para a atuação de psicólogos nos Núcleos de Apoio à Saúde da Família (NASF).

No campo da assistência à saúde mental nos serviços de atenção primária, as autoras afirmaram que a atitude fenomenológica se apresenta como contribuição para a prática nesse contexto, na medida em que demanda um questionamento constante da realidade, suspendendo as concepções e julgamentos prévios, para observar os fenômenos que emergem durante as vivências.

Nos Centros de Atenção Psicossocial (CAPS), Peixoto, Mourão e Serpa Junior (2016), consideraram a fenomenologia e a antropologia médica como referencial teórico, ao realizarem uma pesquisa qualitativa com o objetivo de compreender a relação empática entre psiquiatras e pacientes com diagnóstico de esquizofrenia.

O trabalho com psicoterapia de grupo apresenta-se, também, como uma possibilidade de atuação dos psicólogos e, segundo Evangelista (2013), Medard Boss, ainda que muito discretamente, teceu comentários sobre essa prática, em dois momentos de sua obra. O primeiro deles está no registro de um dos seminários de Zollikon, ministrado por Heidegger em 1966. O segundo relato consiste na descrição de Boss sobre suas viagens à Índia e à Indonésia, a convite do diretor da Escola de Medicina da Universidade de Jacarta e pelo Centro Psiquiátrico da Universidade de Lucknow, no Norte da Índia, para ser professor visitante, com o objetivo de ensinar a psicoterapia ocidental para os médicos da Índia, mediante seminários clínicos, supervisões e atendimentos (Evangelista, 2013).

O trabalho da psiquiatra Nise da Silveira foi apresentado e articulado com a fenomenologia por Schleder e Holanda (2015). Os autores entenderam que, apesar da psiquiatra não ter utilizado tal referencial teórico em sua prática com pacientes esquizofrênicos, foi possível perceber aproximações com uma atitude fenomenológica. 
Transtornos psicopatológicos à luz da psicopatologia fenomenológica

Como um fenômeno frequente na sociedade contemporânea, a depressão foi discutida por Leite e Moreira (2009) com base nas contribuições de Tatossian e Tellenbach, que pensaram o typus melancholicus a partir do seu trabalho clínico, colhendo informações embasadas no contato com pacientes que já foram melancólicos. Problematizando também o transtorno depressivo, Bloc, Melo, Leite e Moreira (2015) tomaram a noção de corpo como fio condutor para compreender a experiência vivida de pessoas diagnosticadas com depressão.

Com uma revisão teórica dos principais expoentes da psicopatologia fenomenológica, como Binswanger, Minkowski, Tellenbach e Tatossian, os autores Bloc, Souza e Moreira (2016), apresentaram as contribuições centrais para compreender o fenômeno da depressão.

A noção de tempo vivido foi uma das categorias utilizadas para se refletir sobre a relação entre indivíduo e mundo e, a partir desta relação, Moreira e Bloc (2012) discutiram o transtorno bipolar. Neste transtorno, não há uma vivência fluida do tempo, pois a ligação entre passado, presente e futuro é comprometida. Na mania, o sujeito vive numa pura atualidade, constantemente no presente. Já na melancolia, “[...] vive-se em um passado ou em um futuro alterado, tendo como consequência uma ausência de perspectiva de presente" (Moreira \& Bloc, 2012, p. 449).

Nos artigos analisados, o transtorno obsessivo compulsivo (TOC) foi abordado sob duas maneiras distintas, quando utilizaram o termo "fenomenologia". A primeira delas diz respeito ao uso na medicina, ou seja, para se referir àquilo que se manifesta nas (psico) patologias, tal como o fizeram Berrios (2011) e Meyer et al. (2015).

Diniz et al. (2012) realizaram uma revisão sobre a relação do TOC com o medo e a ansiedade. Os autores se propuseram a "[...] avaliar o grau de sobreposição da fenomenologia e da fisiopatologia do TOC e de outros transtornos de ansiedade, com o intuito de dar suporte ao racional das futuras pesquisas na área" (Diniz et al., 2012, p. 595).

Buscando uma compreensão fenomenológica-existencial do TOC, Santos (2013a), explorou os conceitos de culpa e angústia, em Boss e Von Gebsattel. Partindo do Dasein heideggeriano e da condição de ser-para-a-morte, a angústia seria o desvelamento desta, gerando um sentimento de "desorientação frente à existência" (s/p), sem se dirigir a alguma coisa específica. 
A culpa também é condição ontológica, em que o Dasein, não sendo "genuinamente autêntico" (s/p), se ocupa do ter-que-ser-si-mesmo. Na impossibilidade do homem de ser de forma plena em si-mesmo, é que se manifesta a culpa (Santos, 2013a). Posto isso, no TOC, a angústia e a culpa ficariam em evidência, "na medida em que o existente nega suas potencialidades de realização, desveladas pela sua situação de ter-queser-si-mesmo, e se sente em débito para consigo mesmo" ( $\mathrm{s} / \mathrm{p})$.

Para Von Gebsattel (1938/1967, citado por Santos, 2013a), o TOC é compreendido como uma alteração na temporalidade do sujeito, que teria seu devir prejudicado, permanecendo preso ao passado e perdendo a dimensão de futuro.

Ao analisarem o caso Ellen West, de Binswanger, Moreira, Cruz e Vasconcelos (2005), articularam os principais conceitos da análise existencial e da psicopatologia. As análises do caso feitas pelas autoras iniciaram a partir das formas de existir de Ellen West no Umwelt (mundo físico, o ambiente no qual estamos inseridos), no Mitwelt (mundo social, onde ocorrem as relações com as outras pessoas) e no Eigenwelt (mundo pessoal, o eu e o corpo). Vinda de uma complicada relação com seus pais, a constituição de seu Eigenwelt se dá em oposição ao Mitwelt, aspecto este que, segundo as autoras, limitava suas possibilidades existenciais.

Sobre os transtornos do comportamento alimentar, Charbonneau e Moreira (2013) discutiram, em seu artigo, o transtorno do comportamento alimentar hiperfágico e as adicções, com base numa perspectiva fenomenológica e antropológica, sem restringir suas análises a um único sentido. Os autores concluíram que considerar os transtornos do comportamento alimentar como uma forma comum de adicção empobrece, em alguns casos, a noção de adicção relativa a esses transtornos. Em seu aspecto não adiccional, os transtornos do comportamento alimentar possuem interessantes questões antropológicas, como o fato de o alimento organizar a vida e o espaço social e promover relações com todos os processos (compras, preparação, refeição) que o envolvem.

Compreendida como um transtorno psicossomático, a disfunção erétil foi discutida por De Zorzi, Bloc e Boris (2015), a partir da fenomenologia de Merleau-Ponty e da psicopatologia fenomenológica de Tatossian, que proporcionaram um novo entendimento do transtorno, considerando-o em sua totalidade, expressividade e intencionalidade.

Refletindo sobre casos de sofrimento psíquico grave e as experiências de caráter espiritual na clínica psicológica, Mano e Costa (2015) apresentaram vinhetas de 
atendimentos, baseando suas discussões em autores como Husserl, Edith Stein, Tillich, Winnicott, dentre outros.

A fenomenologia, de acordo com Martins (2009) serve como um auxílio, a partir de seus recursos próprios, para fazer um trabalho melhor na clínica, ao receber seus pacientes e suas realidades. Através dos conceitos de res extensa e res cogitans, é possível pensar a clínica das psicoses e a ideia de perda de realidade, que comumente se apresenta nessas situações. Tomando como referência a obra de Husserl, "Fenomenologia da Constituição", na qual o filósofo demonstrou que a realidade das coisas se constitui a partir de esquemas, há nos esquizofrênicos uma alteração desses esquemas, o que faz com que eles se questionem todo o tempo sobre o que está acontecendo (Martins, 2009). Por fim, para exemplificar suas afirmações, o autor evidenciou resultados da aplicação do teste de Rorschach, mas não deixou muito claras suas conclusões.

\section{Conceitos desenvolvidos na psicopatologia fenomenológica}

Nesta categoria, foram elencados artigos que tratam de questões relativas à psicopatologia fenomenológica e seus conceitos e proposições que se aproximam e podem contribuir para sua fundamentação e desenvolvimento.

Moreira (2011) traçou uma linha do tempo, baseando-se em Jaspers que, com a publicação da obra Psicopatologia Geral (1913) e influenciado pelo método de Husserl, situou a psicopatologia como uma área do conhecimento independente. Todavia, no caso de Jaspers, ainda não se falava de uma psicopatologia fenomenológica. Foi com Binswanger que, de acordo com a autora, teve início a psicopatologia fenomenológica, enquanto movimento de compreensão das alterações psicopatológicas, à luz da fenomenologia filosófica de autores como Husserl e Heidegger. Influenciado pelos trabalhos de Binswanger e pela Analítica do Dasein de Heidegger, Boss, outro psiquiatra apresentado por Moreira (2011), desenvolveu uma "psicopatologia de inspiração daseinsanalítica" (p. 178).

Karwowski (2015) também apresentou, em seu artigo, uma perspectiva histórica da psicopatologia fenomenológica, expondo suas bases, conceitos, influências e desdobramentos. Rovaletti (2015) complementou a discussão dos autores referidos, ao indicar os movimentos que ocorreram na psiquiatria e a progressiva transição entre a psiquiatria baseada em evidências e a psiquiatria baseada em valores/narrativas. O percurso dos trabalhos de Binswanger foi apresentado por Pita e Moreira (2013), ao relatarem as 
três fases de seu pensamento, de acordo com a divisão feita por Arthur Tatossian. Na primeira fase, Binswanger desenvolveu uma antropologia fenomenológica; na segunda fase, se aproximou de Heidegger, tomando o conceito de Dasein e, na terceira fase, chamada pelas autoras de "reviravolta fenomenológica" (p. 684), tratou de uma fenomenologia genética.

Binswanger se apropriou dos trabalhos de Heidegger para propor a Dasensanalyse, afirmou Souza Júnior (2009), ao discutir esse fato, e apontou que o psiquiatra recebeu críticas do filósofo, que admitia existir na Daseinsanalyse elementos de sua analítica do Dasein, mas também muitos mal-entendidos, como o fato de Binswanger ter alcançado apenas uma ideia geral e confusa do que diz respeito à estrutura do Dasein.

Chammond (2011) acrescentou aos estudos mencionados por Souza Júnior (2009) a discussão sobre a psicopatologia do espaço vivido, segundo Binswanger, e discutiu o conceito de direção de sentido, considerada como uma "estrutura ontológica da existência" (Chammond, 2011, p. 5).

A fenomenologia hermenêutica de Heidegger, bem como a Daseinsanalyse de Boss, foram discutidas por Feijoo e Mattar (2015), ao colocarem em questão a psicossomática e sua tradicional dicotomia entre soma e psique e a noção de causalidade inerente a ela.

A obra de diversos psiquiatras foi integrada por Arthur Tatossian, psiquiatra francês, reconhecido como referência em quatro artigos selecionados para essa categoria (Bloc \& Moreira, 2013; 2014; Moreira, 2011; 2016). Apresentado por Moreira (2011), como o representante de uma "psicopatologia contemporânea do Lebenswelt" (p.180), Tatossian se preocupou em desenvolver uma psicopatologia fenomenológica da clínica e para a clínica, ressaltando que a relação entre a fenomenologia filosófica e a fenomenologia clinica deveria ser de implicação e não de aplicação, tendo como prioridade, em sua prática, o contato com os pacientes (Bloc \& Moreira, 2013; 2014; Moreira, 2011; 2016).

O referido psiquiatra discutiu questões como a relação entre sintoma e fenômeno, afirmando que experiência é, nesta perspectiva, a meta a ser alcançada e não o ponto de partida, o que remete à ideia de movimento constante, em que novas experiências apontam para a compreensão do vivido dos pacientes (Bloc \& Moreira, 2013).

Holanda (2010) discorreu sobre as noções de consciência e inconsciente, em seu artigo. Para a fenomenologia, a consciência é ato, movimento, e não pode, segundo o autor, 
ser tratada como um objeto. Ao falar do inconsciente, lembrou que o conceito de intencionalidade, proposto por Brentano e retomado por Husserl, foi responsável por retirar a ideia de interioridade da base da psicologia.

As referências à fenomenologia de Merleau-Ponty e suas articulações com a psicopatologia e a psicologia foram frequentes em diversos artigos encontrados nesta revisão (Cremasco, 2009; Telles \& Moreira, 2014; Vieira \& Furlan, 2011). As associações entre a fenomenologia merleau-pontyana e os transtornos psicopatológicos foram discutidas por Vieira e Furlan (2011), com base na experiência do corpo próprio e sua relação com os outros, em sua função primordial de formação de sentidos no mundo. A noção de corpo foi uma importante contribuição de Merleau-Ponty, também para a psicologia, ao fornecer, como aponta Cremasco (2009), as bases para as psicoterapias humanistas existenciais e um diálogo com o próprio existencialismo.

A fenomenologia de Merleau-Ponty também foi referida no artigo de Silveira e Merlo (2014), juntamente com Sartre e Heidegger, para discutir questões relativas à linguagem e à experiência, tendo, como recorte de sua pesquisa, o uso da palavra "medo" e a forma como esta perpassa o discurso dos trabalhadores de indústrias frigoríficas na região sul do país.

Telles e Moreira (2014) propuseram aproximações da fenomenologia de MerleauPonty com a psicopatologia cultural, área que, segundo as autoras, “[...] contempla estudos em psicologia, psiquiatria, antropologia e demais áreas do saber, que convergem em pesquisas concernentes às relações entre questões culturais e psicopatologia" (p. 205). Os trabalhos de Kleinman são indicados como clássicos para as discussões nessa perspectiva, principalmente através dos conceitos de disease, illness e sickness.

Os trabalhos de López-Silva (2014) e Santos (2013b) discutiram, sob as perspectivas de Thomas Szasz e Luis Martin-Santos, respectivamente, a noção de doença mental. Tomas Szasz, segundo López-Silva (2014), criticou tanto a prática psiquiátrica, quanto a sustentação filosófica do conceito de doença mental, ao afirmar que o problema do modelo clássico de psiquiatria é considerar apenas a origem orgânica dos transtornos psicopatológicos. A proposta seria, portanto, "ampliar os limites das explicações em psiquiatria [...] tornando-se necessário entender a estrutura fundamental da experiência consciente [...]" (López-Silva, 2014, p. 239-240).

O trabalho de Luís Martin-Santos é, de acordo com Santos (2013b), pouco conhecido no Brasil, apesar de seu valor para a psiquiatria e psicoterapia de língua 
espanhola. Para a psicoterapia, as contribuições de Martin-Santos têm como centro a psicanálise existencial de Sartre, da qual também traz para suas discussões a noção de liberdade.

No texto de Franco (2008), a referência à fenomenologia se fez associada à psicanálise e à psicopatologia fundamental, para discutir a crise epistemológica sobre a psicanálise e as ciências humanas em geral. Franco afirmou que nenhuma filosofia reflexiva se aproximou tanto da psicanálise como a fenomenologia de Husserl e de alguns dos que o seguiram.

A psicopatologia também foi situada em um contexto de mudanças epistemológicas decorrentes do pós-estruturalismo, segundo Iorio (2005). Nesta transição entre paradigmas, o autor destacou a psicopatologia fundamental de Pierre Fédida, as fenomenologias hermenêuticas de Heidegger e Gadamer, bem como Ricoeur e Lévinas, que marcaram a "revalorização do enfoque compreensivo" (Iorio, 2005, p. 376) e da compreensão empática do pathos.

Aragona e Marková (2015) indicaram e discutiram a crise na psiquiatria contemporânea, problematizando a noção de sintomas mentais. Para os autores, os trabalhos em psicopatologia, psiquiatria e psicologia não podem se limitar a aspectos neurobiológicos, devendo ser consideradas, também, as experiências subjetivas, as relações entre pacientes e médicos, numa construção hermenêutica, tal como propõe a Escola de Cambridge.

$\mathrm{Na}$ esteira dos movimentos antipsiquiátricos do século $\mathrm{XX}$, Spohr e Schneider (2009) discutiram as influências de Sartre em tais movimentos. O filósofo, inicialmente inspirado na obra de Jaspers, se posicionou criticamente frente ao modelo psiquiátrico predominante e foi inspiração para os trabalhos de psiquiatras fenomenológicos. A obra de Jaspers, segundo Manganaro (2006), formou, "pelo menos, três gerações de psiquiatras, preparando o terreno para o grande exército de psicopatologistas destinados a receber e desenvolver a influência de E. Husserl e de M. Heidegger” (p. 86). Na Itália, um dos países com forte representação na luta antimanicomial, a psiquiatria fenomenológica-existencial entrou em cena por meio dos trabalhos de Bruno Callieri, um dos pioneiros na introdução da fenomenologia no país (Manganaro, 2006). 
Pesquisas fenomenológicas e psicopatologia fenomenológica: questões de método

Nesta categoria, foram reunidos artigos que discutissem ou utilizassem, em suas práticas e pesquisas em psicologia e psicopatologia, um método com inspirações fenomenológicas. Jaspers (1912/2015) apresentou a ideia de como o método fenomenológico de Husserl pode ser voltado para o trabalho em psicopatologia, indicando e discutindo conceitos baseados em atividade com o referido método.

Moreira (2004) propôs uma articulação entre o método fenomenológico de Merleau-Ponty e a pesquisa em psicopatologia. Como contribuições a este modelo metodológico, Moreira e Cavalcante Junior (2008) realizaram interlocuções com a etnografia. A fenomenologia e a etnografia se tocam no ponto crucial, para ambos os métodos, qual seja: a possibilidade de compreender a experiência de adoecer em diferentes perspectivas, diferentes lentes. Epistemologicamente não é possível juntar os métodos fenomenológico e etnográfico. O que os autores propuseram, portanto, foi a incorporação de instrumentos da pesquisa etnográfica para complementar as entrevistas utilizadas no método fenomenológico. Assim, além das entrevistas, passou-se a utilizar o diário de campo, no qual o pesquisador relata sua experiência e observações resultantes de sua presença em campo.

$\mathrm{Na}$ pesquisa realizada por De Zorzi e Boris (2013), os autores investigaram a experiência da disfunção erétil. No artigo, discutiram a experiência de dois dos sujeitos colaboradores, com base da fenomenologia de Merleau-Ponty, a partir da análise dos contornos diacríticos que consistem na "[...] composição dos gestos, silêncios, tons de voz, risos e enunciações deixadas como rastros ou imprimidas pelo sujeito enunciador, que ainda não estão na ordem do "dar-se conta" e que dão ênfase e significação ao discurso" (p. 170).

A experiência de pessoas que tentaram suicídio foi trabalhada por Rocha, Boris e Moreira (2012), a partir de entrevistas semiestruturadas e guiadas pelo método fenomenológico crítico. Moreira, Mesquita e Melo (2010) tiveram como objetivo compreender a experiência vivida por pessoas com Aids e que passaram por processos de internação hospitalar. Melo e Moreira (2008) almejaram compreender o fenômeno da queixa depressiva em adolescentes, porém, diferente dos estudos anteriores, não utilizaram a entrevista como instrumento para coleta de dados, mas os prontuários dos pacientes, analisando as transcrições das entrevistas dos processos de triagem. 
Utilizando o método fenomenológico-hermenêutico, El-Jaick, Berg, Peixoto e Serpa Junior (2016) objetivaram compreender a experiência de usuários de um serviço de saúde, ao participarem de um projeto na mesma instituição, em que atuavam como educadores.

Além de sua utilização nas pesquisas, o método fenomenológico de investigação foi discutido por Colpo (2013) em suas articulações com as práticas clínicas. A fenomenologia, como método, indica os caminhos para pensar o que o autor chamou de "fenomenologia regional" (p.105), citando, como exemplo, a psicopatologia.

A relação entre os psicólogos e psiquiatras com seus pacientes foi trabalhada por Serpa Junior, Leal, Louzada e Silva Filho (2007), alicerçada no método fenomenológico, ao relatarem um estudo de caso a partir da proposta de uma atividade prática com alunos do curso de Psicologia, na qual os autores buscaram um distanciamento da compreensão das psicopatologias, com foco apenas nos sintomas e predominantemente descritiva, que deu a base para as classificações psiquiátricas modernas para favorecer a compreensão dos transtornos psicopatológicos baseada no relato daqueles que os experienciam.

Com esta revisão sistemática da literatura, constatou-se que, em um intervalo de 12 anos (2004-2016), houve poucas produções científicas publicadas nessa área de conhecimento, nos periódicos brasileiros indexados nas bases de dados consultadas. Todavia, de acordo com as datas em que a maioria dos artigos foi publicada - entre os anos de 2009 e 2016 -, supõe-se que esteja ocorrendo a redescoberta e a intenção de investir na fenomenologia como uma possibilidade teórica e metodológica para as práticas em psicologia.

Observou-se que a base metodológica e filosófica se estendeu em direções diversas, mas, essencialmente, se manteve em conformidade e estreita relação com as produções nos campos da psiquiatria e da psicologia, onde repousam a maioria das publicações.

Os pontos de convergência entre os artigos foram inúmeros, mas existiu, através da fenomenologia, o intento de proporcionar uma posição crítica frente às situações. $\mathrm{O}$ tom crítico foi posto de maneira mais clara nos artigos que tomaram a fenomenologia de Merleau-Ponty como inspiração teórica e/ou metodológica.

Em sua fenomenologia da ambiguidade, ao propor recolocar as essências na existência, Merleau-Ponty (1945/2006) ressaltou a mútua constituição entre homem e mundo, a partir da qual não podemos considerar o primeiro separado do segundo, haja vista que todo o universo da ciência é construído sobre o mundo vivido, e, para pensar a 
própria ciência com rigor e apreciar seu sentido exato e seu alcance, é preciso, primeiramente, despertar essa experiência do mundo da qual ela é a expressão segunda (p. $3)$.

Considerar uma prática que tem a fenomenologia como método, como um fio condutor no qual se sustentam as intervenções, significa ter a experiência como objetivo, posicionando-se frente aos fenômenos com uma postura que os interroga, mas se mantém aberta para recebê-los da forma como se apresentam, tal como indicou Tatossian (1979/2006), ao afirmar que "[...] para a fenomenologia, a experiência não se coloca de início, mas na chegada de seu desenvolvimento; ela não é terminus a quo, mas terminus ad quem" (p. 37, grifos do autor).

Quando se toma a fenomenologia como inspiração metodológica e base filosófica, seja nos métodos de pesquisa, no trabalho clínico, ou nas práticas educativas, significa trazer as narrativas para a primeira pessoa, deixando que cada um narre sua experiência. Ela, a fenomenologia, abre espaço para a diversidade, como foi possível observar através dos pensadores que compõem este campo filosófico, seus conceitos e as áreas distintas para as quais se direcionam.

A produção de trabalhos teóricos que correspondem à maioria dos trabalhos aqui apresentados foi, sem dúvida, fundamental para a divulgação e a possibilidade de compreensão da psicopatologia fenomenológica e da fenomenologia. De igual relevância são as pesquisas que trazem com mais frequência a psicopatologia fenomenológica para aspectos da prática clínica, seja com as psicopatologias ou em contextos do trabalho social e de assistência em saúde.

\section{Considerações finais}

A utilização da revisão sistemática da literatura, como método, forneceu o rigor necessário para apresentar o cenário das produções em psicopatologia fenomenológica indexadas em bases de dados do Brasil. Foi identificado, ao longo da pesquisa, um campo com muitas alternativas, dadas as possibilidades de inserção para a psicopatologia fenomenológica, mas, também, com muitos desafios e intenso trabalho a ser realizado. Esta potencialidade de articulação pode ser representada para além do que já está publicado, voltando-se para o que ainda está em processo de construção ou não aparece nas grandes bases de dados. 
Observou-se, no decorrer da análise, que os trabalhos que articulam a teoria da psicopatologia fenomenológica com a prática clínica da psicologia e da psiquiatria ainda representam uma lacuna no campo das pesquisas em psicopatologia fenomenológica.

Em conformidade com a atitude fenomenológica, não se pretendeu oferecer respostas definitivas, mas abrir novas possibilidades e levantar questões sobre o cenário das pesquisas em psicopatologia fenomenológica no Brasil. Concluiu-se que, ainda que essas pesquisas se encontrem em crescimento, merecem amplo investimento na ampliação de publicações em revistas indexadas nas bases de dados brasileiras e internacionais. 


\section{Referências}

Anthony, S. M. R. (2009a). A criança com transtorno de ansiedade: seus ajustamentos criativos defensivos. Revista da Abordagem Gestáltica, 15(1), 55-61.

Anthony, S. M. R. (2009b). Os ajustamentos criativos da criança em sofrimento: uma compreensão da gestalt-terapia sobre as principais psicopatologias da infância. Estudos e Pesquisas em Psicologia, 9(2), 356-375.

Antúnez, A. E. A., \& Safra, G. (2014). El poeta, el filósofo, el médico: estúdio del sufrimiento. Revista Latinoamericana de Psicopatologia Fundamental, 17(2), 363-376.

Antúnez, A. E. A., \& Wondracek, K. H. K. (2012). Fenomenologia em Michel Henry: implicações na psicopatologia e psicoterapia. Revista da Abordagem Gestáltica, 18(1), $3-12$.

Aragona, M., \& Marková, I. S. (2015) The hermeneutics of mental symptoms in the Cambridge School. Revista Latinoamericana de Psicopatologia Fundamental, 18(4), 599-618.

Berrios, G. E. (2011). O estupor revisitado. Revista Latinoamericana de Psicopatologia Fundamental, 14(1), 145-165.

Berwanger, O., Suzumura, E. A., Buehler, A. M., \& Oliveira, J. B. (2007). Como avaliar criticamente revisões sistemáticas e metanálises? Revista Brasileira de Terapia Intensiva, 19(4), 475-480.

Bloc, L., \& Moreira, V. (2013). Sintoma e fenômeno na psicopatologia fenomenológica de Arthur Tatossian. Revista Latinoamericana de Psicopatologia Fundamental, 16(1), 2841 .

Bloc, L., \& Moreira, V. (2014). Arthur Tatossian: um estudo biográfico. Revista da Abordagem Gestáltica, 20(2), 181-188.

Bloc, L., Melo, A. K, S, Leite, E., \& Moreira, V. (2015) Fenomenologia do corpo vivido na depressão. Estudos de Psicologia (Natal), 20(4), 217-228.

Bloc, L., Souza, C., \& Moreira, V. (2016) Phenomenology of depression: contributions of Minkowski, Binswanger, Tellenbach and Tatossian. Estudos de Psicologia (Campinas), $33(1), 107-116$

Chamond, J. (2011). Fenomenologia e psicopatologia do espaço vivido segundo Ludwig Binswanger: uma introdução. Revista da Abordagem Gestáltica, 17(1), 3-7.

Charbonneau, G. (2010). Introduction à la psychopathologie phénoménologique. Paris: MJW Fédition. 
Charbonneau, G., Moreira, V. (2013). Fenomenologia do transtorno do comportamento alimentar hiperfágico e adicções. Revista Latinoamericana de Psicopatologia Fundamental, 16(4), 529.

Colpo, M. O. (2013). O método fenomenológico de investigação e as práticas clínicas em Psicologia. Psicologia Revista (São Paulo). Revista da Faculdade de Ciências Humanas e da Saúde, 22(1), 101-118.

Coordenação de Aperfeiçoamento de Pessoal de Nível Superior (CAPES) (2014). Classificação da produção intelectual. Recuperado de http://www.capes.gov.br/avaliacao/instrumentos-de-apoio/classificacao-da-producaointelectual

Cremasco, M. V. F. (2009). Algumas contribuições de Merleau-Ponty para a Psicologia em Fenomenologia da percepção. Revista da Abordagem Gestáltica, 15(1), 51-54.

De Zorzi, F., \& Boris, G. D. J. B. (2013). Disfunção erétil e fenomenologia: o corpo vivido em seus contornos diacríticos. Revista da Abordagem Gestáltica, 19(2), 167-175.

De Zorzi, F., Bloc, L. \& Boris, G. D. J. B. (2015) O corpo em expressão na disfunção erétil: as contribuições de Merleau-Ponty e Tatossian. Revista do NUFEN, 7(1), 48-66.

De-la-Torre-Ugarte-Guanilo, M., Takahashi, R., \& Bertolozzi, M. (2011). Revisão sistemática: noções gerais. Revista da Escola de Enfermagem da USP, 45(5), 12601266.

Diniz, J. B., Miguel, E. C., de Oliveira, A. R., Reimer, A. E., Brandão, M. L., de Mathis, M. A., ... \& Hoexter, M. Q. (2012). Desenhando as novas fronteiras para a compreensão do transtorno obsessivo-compulsivo: uma revisão de sua relação com o medo e a ansiedade. Revista Brasileira de Psiquiatria, 34(Suppl 1), S81-S103.

El-Jaick, F. S., Berg, K. B., Peixoto, M. M., \& Serpa Junior, O. D. (2016) Usuários da saúde mental como educadores: o que suas narrativas podem nos ensinar? Interface Comunicação, Saúde e Educação, 20(56), 227-238.

Evangelista, P. (2013). Um breve comentário de Medard Boss sobre psicoterapia de grupo: a transferência na situação grupal. Revista da Abordagem Gestáltica, 19(2), 212-219.

Feijoo, A. M. L. C., Mattar, C. M. (2015) A desconstrução da psicossomática na análise existencial de Heidegger e Boss. Revista Latinoamericana de Psicopatologia Fundamental, 18(4), 651-662. 
Franco, S. D. G. (2008). Críticas à psicanálise, o enfoque fenomenológico, a psicopatologia fundamental. Latin American Journal of Fundamental Psychopathology On Line, 5(1), 118-127.

Galli, L. M. P. (2009). Um olhar fenomenológico sobre a questão da saúde e da doença: a cura do ponto de vista da Gestalt-terapia. Estudos e Pesquisas em Psicologia, 9(1), 5971.

Guede, D. D., Monteiro-Leitner, J., \& Machado, K. C. R. (2008). Rompimento amoroso, depressão e auto-estima: estudo de caso. Revista Mal-Estar e Subjetividade, 8(3), 603643.

Holanda, A. (2010). Notas para uma reflexão sobre consciência e inconsciente na fenomenologia. Revista da Abordagem Gestáltica, 16(1), 45-53.

Iorio, A. L. (2005). Psicopatologia e pós-estruturalismo: convivendo com novas problemáticas. Revista Mal-estar e Sujetividade, 5(1), 361-381.

Jaspers, K. (2015). A direção de pesquisa fenomenológica na psicopatologia. Revista da Abordagem Gestáltica - Phenomenological Studies, 21(1), 97-105.

Karwowski, S. L. (2015). Por um entendimento do que se chama psicopatologia fenomenológica. Revista da Abordagem Gestáltica - Phenomenological Studies, 21(1), $62-73$.

Leite, M. E., \& Moreira, V. (2009). A contribuição de Tellenbach e Tatossian para uma compreensão fenomenológica da depressão. Arquivos Brasileiros de Psicologia, 61(3), 46-56.

López-Silva, P. (2014). Consideraciones críticas sobre la propuesta de Thomas Szasz. Entre filosofía de la mente, fenomenología y psiquiatría. Revista Latinoamericana de Psicopatologia Fundamental, 17(2), 234-250.

Manganaro, P. (2006). A psiquiatria fenomenológico-existencial na Itália. Memorandum, $10,85-92$.

Mano, R. P., \& Costa, I. I. (2015) "Deus não morreu e o diabo existe": reflexões fenomenológicas sobre a experiência espiritual e o sofrimento psíquico grave. Revista da Abordagem Gestáltica, 21(2), 162-176.

Martins, F. M. D. M. C. (2009). Esquema da coisa (das Ding) de Husserl e a Esquizofrenia. Revista da Abordagem Gestáltica, 15(2), 99-102. 
Melo, A. K. D. S., Boris, G. D. J. B., \& Stoltenborg, V. (2009). Reconstruindo sentidos na interface de histórias: uma discussão fenomenológico-existencial da constituição do sujeito borderline. Revista da Abordagem Gestáltica, 15(2), 133-144.

Melo, A. K. S. \& Moreira, V. (2008). Fenomenologia da queixa depressiva em adolescentes: um estudo crítico-cultural. Aletheia, 27, 51-64.

Merleau-Ponty, M. (2006). Fenomenologia da percepção. São Paulo: Martins Fontes. (Original publicado em 1945).

Meyer, L. F., Taborda, J. G. V., Costa, F. A., Soares, A. L. A. G., Mecler, K., Valença, A. L. (2015). Phenomenological aspects of the cognitive rumination construct. Trends in Psychiatry and Psycotherapy, 37(1), 20-26.

Moher D, Liberati A, Tetzlaff J, Altman DG (2009). Preferred Reporting Items for Systematic Reviews and Meta-Analyses: The PRISMA Statement. Ann Intern Med. $151,264-269$.

Moreira, V. (2004). O método fenomenológico de Merleau-Ponty como ferramenta crítica na pesquisa em psicologia. Psicologia: Reflexão e Crítica, 17(3), 447-456.

Moreira, V. (2011). A contribuição de Jaspers, Binswanger, Boss e Tatossian para a psicopatologia fenomenológica. Revista da Abordagem Gestáltica, 17(2), 172-184.

Moreira, V. (2016) From essence to Lebenswelt as a method in phenomenological psychopathology. Estudos de Psicologia (Campinas), 33(3), 403-411.

Moreira, V., \& Bloc, L. (2012). Fenomenologia do tempo vivido no transtorno bipolar. Psicologia: Teoria e Pesquisa, 28(4), 443-450.

Moreira, V., \& Cavalcante Junior, F. S. (2008). O método fenomenológico crítico (ou mundano) na pesquisa em psico(pato)logia e a contribuição da etnografia. Estudos $e$ Pesquisas em Psicologia, 8(2), 245-260.

Moreira, V., Cruz, A. V. H., \& Vasconcelos, L. B. (2005). O caso Ellen West de Binswanger: fenomenologia clínica de uma existência inautêntica. Revista Mal Estar e Subjetividade, 5(2), 382-396.

Moreira, V., Mesquita, S., \& Melo, A. K. (2010). A experiência de hospitalização vivida por pacientes com AIDS. Boletim de Psicologia, 60(133), 153-166.

Peixoto, M. M., Mourão, A. C. N., \& Serpa Junior, O. D. (2016). O encontro com a perspectiva do outro: empatia na relação entre psiquiatras e pessoas com diagnóstico de esquizofrenia. Ciência \& Saúde Coletiva, 21(3), 881-890. 
Pereira A. L, Bachion M. M. (2006). Atualidades em revisão sistemática de literatura, critérios de força e grau de recomendação de evidência. Revista Gaúcha de Enfermagem, 27(4), 491-498.

Pita, J., \& Moreira, V. (2013). As fases do pensamento fenomenológico de Ludwig Binswanger. Psicologia em Estudo, 18(4), 679-687.

Rocha, M. A. S. D., Boris, G. D. J. B., \& Moreira, V. (2012). A experiência suicida numa perspectiva humanista-fenomenológica. Revista da Abordagem Gestáltica, 18(1), 69-78.

Rovaletti, M. L. (2015) Alcance y significación da psico(pato)logía fenomenológica. Revista da Abordagem Gestáltica, 21(2), 117-123.

Sampaio, R. F. \& Mancini, M. C. (2007). Estudos de revisão sistemática: um guia para síntese criteriosa de evidência científica. Revista Brasileira de Fisioterapia, 11(1), 8389.

Santos Filho, J. M. \& Costa, V. E. S. M. (2016). Encontrando um modo de ser esquizofrênico: arte e técnica na gestalt-terapia. Revista da Abordagem Gestáltica, 22(1), 27-36.

Santos, G. A. O. (2013a). A angústia e a culpa no transtorno obsessivo-compulsivo: uma compreensão fenomenológico-existencial. Revista da Abordagem Gestáltica, 19(1), 8591.

Santos, G. A. O. (2013b). Contribuições da obra de Luis Marti-Santos para a psicoterapia. Revista do NUFEN, 5(2), 64-82.

Schleder, K. S. \& Holanda, A. F. (2015) Nise da Silveira e o enfoque fenomenológico. Revista da Abordagem Gestáltica, 21(1), 49-61.

Schneider, D. (2009). Caminhos históricos e epistemológicos da Psicologia: contribuição da fenomenologia e existencialismo. Cadernos Brasileiros de Saúde Mental, 1(2), 6276.

Serpa Junior, O. D., Leal, E. M., Louzada, R. D. C. R., \& Silva Filho, J. F. (2007). A inclusão da subjetividade no ensino da Psicopatologia. Interface - Comunicação, Saúde e Educação, 11(22), 207-22.

Silva, N. H. L. P., \& Cardoso, C. L. (2013). Contribuições da fenomenologia de Edith Stein para a atuação do psicólogo nos Núcleos de Apoio à Saúde da Família (NASF). Revista Latinoamericana de Psicopatologia Fundamental, 16(2), 246-259.

Silveira, A. L. \& Merlo, A. R. C. (2014) O medo: expressão de um coletivo de trabalhadores. Fractal: Revista de Psicologia, 26(2), 349-364. 
Souza Júnior, N. J. (2009). Analítica do dasein e daseinsanalyse. Revista do NUFEN, 1(1), 29-39.

Souza, C. P. D., Callou, V. T., \& Moreira, V. (2013). A questão da psicopatologia na perspectiva da abordagem centrada na pessoa: diálogos com Arthur Tatossian. Revista da Abordagem Gestáltica, 19(2), 189-197.

Spohr, B., \& Schneider, D. R. (2009). Bases epistemológicas da antipsiquiatria: a influência do Existencialismo de Sartre. Revista da Abordagem Gestáltica, 15(2), 115125.

Tatossian, A. (2006). A fenomenologia das psicoses (J.C. Freire, trad. e V. Moreira, rev. Tec.). São Paulo: Escuta. (Obra original publicada em 1979).

Telles, T. C. B., \& Moreira, V. (2014). A lente fenomenológica de Merleau-Ponty para a Psicopatologia Fundamental. Psicologia: Teoria e Pesquisa, 30(2), 205-212.

Tenório, C. M. D. (2012). As psicopatologias como distúrbios das funções do self: uma construção teórica na abordagem gestáltica. Revista da Abordagem Gestáltica, 18(2), 224-232.

Vieira, M. G., \& Furlan, R. (2011). Algumas considerações sobre psicopatologia na filosofia de Merleau-Ponty. Ágora: Estudos em Teoria Psicanalítica, 14(1), 129-141. 
Anexo 1. Relação de artigos analisados

\begin{tabular}{|c|c|c|c|}
\hline Autor & Título do artigo & Periódico publicado & Ano de publicação \\
\hline 1. Anthony, S. M. R. & $\begin{array}{l}\text { A criança com transtorno } \\
\text { de ansiedade: seus } \\
\text { ajustamentos criativos } \\
\text { defensivos }\end{array}$ & $\begin{array}{l}\text { Revista da } \\
\text { Abordagem } \\
\text { Gestáltica }\end{array}$ & 2009 \\
\hline 2. Anthony, S. M. R. & $\begin{array}{l}\text { Os ajustamentos } \\
\text { criativos da criança em } \\
\text { sofrimento: } \\
\text { compreensão da } \\
\text { terapia sestalt- } \\
\text { principais } \\
\text { psicopatologias as da } \\
\text { infância }\end{array}$ & $\begin{array}{l}\text { Estudos e Pesquisas } \\
\text { em Psicologia }\end{array}$ & 2009 \\
\hline $\begin{array}{l}\text { 3. Antúnez, A. E. A., \& } \\
\text { Wondracek, K. H. K }\end{array}$ & $\begin{array}{lr}\text { Fenomenologia } & \text { em } \\
\text { Michel } & \text { Henry: } \\
\text { implicações } & \text { na } \\
\text { psicopatologia } & \text { e } \\
\text { psicoterapia } & \end{array}$ & $\begin{array}{l}\text { Revista da } \\
\text { Abordagem } \\
\text { Gestáltica }\end{array}$ & 2012 \\
\hline $\begin{array}{l}\text { 4. Antúnez, A. E. A., \& } \\
\text { Safra, G. }\end{array}$ & $\begin{array}{l}\text { El poeta, el filósofo, el } \\
\text { médico: estúdio del } \\
\text { sufrimiento }\end{array}$ & $\begin{array}{l}\text { Revista } \\
\text { Latinoamericana de } \\
\text { Psicopatologia } \\
\text { Fundamental }\end{array}$ & 2014 \\
\hline $\begin{array}{c}\text { 5. Aragona, M., \& } \\
\text { Marková, I. S. }\end{array}$ & $\begin{array}{l}\text { The hermeneutics of } \\
\text { mental symptoms in the } \\
\text { Cambridge School }\end{array}$ & $\begin{array}{l}\text { Revista } \\
\text { Latinoamericana de } \\
\text { Psicopatologia } \\
\text { Fundamental }\end{array}$ & 2015 \\
\hline 6. Berrios, G. E. & O estupor revisitado & $\begin{array}{l}\text { Revista } \\
\text { Latinoamericana de } \\
\text { Psicopatologia } \\
\text { Fundamental }\end{array}$ & 2011 \\
\hline 7. Bloc, L., \& Moreira, V. & $\begin{array}{l}\text { Sintoma e fenômeno na } \\
\text { psicopatologia } \\
\text { fenomenológica } \\
\text { Arthur Tatossian }\end{array}$ & $\begin{array}{l}\text { Revista } \\
\text { Latinoamericana de } \\
\text { Psicopatologia } \\
\text { Fundamental }\end{array}$ & 2013 \\
\hline 8. Bloc, L., \& Moreira, V. & $\begin{array}{l}\text { Arthur Tatossian: um } \\
\text { estudo biográfico }\end{array}$ & $\begin{array}{l}\text { Revista } \\
\text { Abordagem } \\
\text { Gestáltica }\end{array}$ & 2014 \\
\hline
\end{tabular}




\begin{tabular}{|c|c|c|c|}
\hline $\begin{array}{l}\text { 9. Bloc, L., Melo, A. K, } \\
\text { S,; Leite, E., \& } \\
\text { Moreira, V. }\end{array}$ & $\begin{array}{l}\text { Fenomenologia do corpo } \\
\text { vivido na depressão }\end{array}$ & $\begin{array}{l}\text { Estudos de Psicologia } \\
\text { (Natal) }\end{array}$ & 2015 \\
\hline $\begin{array}{l}\text { 10. Bloc, L., Souza, } \\
\text { C., \& Moreira, V. }\end{array}$ & $\begin{array}{l}\text { Phenomenology of } \\
\text { depression: contributions } \\
\text { of Minkowski, } \\
\text { Binswanger, Tellenbach } \\
\text { and Tatossian }\end{array}$ & $\begin{array}{l}\text { Estudos de Psicologia } \\
\text { (Campinas) }\end{array}$ & 2016 \\
\hline 11. Chamond, J. & $\begin{array}{l}\text { Fenomenologia } \\
\text { psicopatologia do espaço } \\
\text { vivido segundo Ludwig } \\
\text { Binswanger: } \\
\text { introdução }\end{array}$ & $\begin{array}{l}\text { Revista da } \\
\text { Abordagem } \\
\text { Gestáltica }\end{array}$ & 2011 \\
\hline $\begin{array}{l}\text { 12. Charbonneau, G., } \\
\text { Moreira, V. }\end{array}$ & $\begin{array}{ll}\text { Fenomenologia do } & \text { do } \\
\text { transtorno } & \text { do } \\
\text { comportamento } \\
\text { alimentar hiperfágico e } \\
\text { adicções }\end{array}$ & $\begin{array}{l}\text { Revista } \\
\text { Latinoamericana de } \\
\text { Psicopatologia } \\
\text { Fundamental }\end{array}$ & 2013 \\
\hline 13. Colpo, M. O. & $\begin{array}{l}\text { O método } \\
\text { fenomenológico de } \\
\text { investigação e as práticas } \\
\text { clínicas em Psicologia. }\end{array}$ & $\begin{array}{ll}\text { Psicologia } & \text { Revista } \\
\text { (São Paulo) } & \end{array}$ & 2013 \\
\hline $\begin{aligned} \text { 14. } & \text { Cremasco, M. V. } \\
\text { F. } & \end{aligned}$ & $\begin{array}{l}\text { Algumas contribuições } \\
\text { de Merleau-Ponty para a } \\
\text { Psicologia } \\
\text { Fenomenologia } \\
\text { percepção }\end{array}$ & $\begin{array}{l}\text { Revista da } \\
\text { Abordagem } \\
\text { Gestáltica }\end{array}$ & 2009 \\
\hline $\begin{array}{l}\text { 15. De Zorzi, F., \& } \\
\text { Boris, G. D. J. B. }\end{array}$ & $\begin{array}{l}\text { Disfunção erétil e } \\
\text { fenomenologia: o corpo } \\
\text { vivido em seus contornos } \\
\text { diacríticos }\end{array}$ & $\begin{array}{l}\text { Revista da } \\
\text { Abordagem } \\
\text { Gestáltica }\end{array}$ & 2013 \\
\hline $\begin{array}{l}\text { 16. De Zorzi, F., } \\
\text { Bloc, L. \& Boris, G. D. } \\
\text { J. B. }\end{array}$ & \begin{tabular}{lr}
\multicolumn{2}{l}{ O corpo em expressão na } \\
disfunção erétil: as \\
contribuições \\
Merleau-Ponty \\
$\begin{array}{lr}\text { Tatossian } & \text { e }\end{array}$
\end{tabular} & Revista do NUFEN & 2015 \\
\hline
\end{tabular}




\begin{tabular}{|c|c|c|c|}
\hline $\begin{array}{l}17 . \quad \text { Diniz, J. B., } \\
\text { Miguel, E. C., de } \\
\text { Oliveira, A. R., } \\
\text { Reimer, A. E., } \\
\text { Brandão, M. L., de } \\
\text { Mathis, M. A., \& } \\
\text { Hoexter, M. Q. }\end{array}$ & $\begin{array}{l}\text { Desenhando as novas } \\
\text { fronteiras para a } \\
\text { compreensão } \\
\text { transtorno obsessivo- } \\
\text { compulsivo: uma revisão } \\
\text { de sua relação com o } \\
\text { medo e a ansiedade }\end{array}$ & $\begin{array}{l}\text { Revista Brasileira de } \\
\text { Psiquiatria }\end{array}$ & 2012 \\
\hline $\begin{array}{l}\text { 18. El-Jaick, F. S., } \\
\text { Berg, K. B., Peixoto, } \\
\text { M. M., \& Serpa Junior, } \\
\text { O. D. }\end{array}$ & $\begin{array}{l}\text { Usuários da saúde mental } \\
\text { como educadores: o que } \\
\text { suas narrativas podem } \\
\text { nos ensinar? }\end{array}$ & $\begin{array}{l}\text { Interface } \\
\text { Comunicação, Saúde } \\
\text { e Educação }\end{array}$ & 2016 \\
\hline 19. Evangelista, P. & $\begin{array}{l}\text { Um breve comentário de } \\
\text { Medard Boss sobre } \\
\text { psicoterapia de grupo: a } \\
\text { transferência na situação } \\
\text { grupal }\end{array}$ & $\begin{array}{l}\text { Revista da } \\
\text { Abordagem } \\
\text { Gestáltica }\end{array}$ & 2013 \\
\hline $\begin{array}{c}\text { 20. Feijoo, A. M. L. } \\
\text { C., Mattar, C. M. }\end{array}$ & $\begin{array}{ll}\text { A desconstrução } & \text { da } \\
\text { psicossomática } & \text { na } \\
\text { análise existencial } & \text { de } \\
\text { Heidegger e Boss } & \end{array}$ & $\begin{array}{l}\text { Revista } \\
\text { Latinoamericana de } \\
\text { Psicopatologia } \\
\text { Fundamental }\end{array}$ & 2015 \\
\hline 21. Franco, S. D. G. & $\begin{array}{l}\text { Críticas à psicanálise, o } \\
\text { enfoque fenomenológico, } \\
\text { a psicopatologia } \\
\text { fundamental }\end{array}$ & $\begin{array}{l}\text { Latin American } \\
\text { Journal of } \\
\text { Fundamental } \\
\text { Psychopathology On } \\
\text { Line }\end{array}$ & 2008 \\
\hline 22. Galli, L. M. P. & $\begin{array}{l}\text { Um olhar } \\
\text { fenomenológico sobre a } \\
\text { questão da saúde e da } \\
\text { doença: a cura do ponto } \\
\text { de vista da Gestalt- } \\
\text { terapia }\end{array}$ & $\begin{array}{l}\text { Estudos e Pesquisas } \\
\text { em Psicologia }\end{array}$ & 2009 \\
\hline $\begin{array}{l}\text { 23. Guede, D. D., } \\
\text { Monteiro-Leitner, J., \& } \\
\text { Machado, K. C. R. }\end{array}$ & $\begin{array}{l}\text { Rompimento amoroso, } \\
\text { depressão e auto-estima: } \\
\text { estudo de caso }\end{array}$ & $\begin{array}{l}\text { Revista Mal-Estar e } \\
\text { Subjetividade }\end{array}$ & 2008 \\
\hline 24. Holanda, A. & $\begin{array}{l}\text { Notas para uma reflexão } \\
\text { sobre consciência e } \\
\text { inconsciente na } \\
\text { fenomenologia }\end{array}$ & $\begin{array}{l}\text { Revista } \\
\text { Abordagem } \\
\text { Gestáltica }\end{array}$ & 2010 \\
\hline
\end{tabular}




\begin{tabular}{|c|c|c|c|}
\hline 25. Iorio, A. L. & $\begin{array}{l}\text { Psicopatologia e pós- } \\
\text { estruturalismo: } \\
\text { convivendo com novas } \\
\text { problemáticas }\end{array}$ & $\begin{array}{l}\text { Revista Mal-estar e } \\
\text { Sujetividade }\end{array}$ & 2005 \\
\hline 26. Jaspers, K. & $\begin{array}{l}\text { A direção de pesquisa } \\
\text { fenomenológica na } \\
\text { psicopatologia }\end{array}$ & $\begin{array}{l}\text { Revista da } \\
\text { Abordagem } \\
\text { Gestáltica } \\
\text { Phenomenological } \\
\text { Studies }\end{array}$ & 2015 \\
\hline 27. Karwowski, S. L. & $\begin{array}{l}\text { Por um entendimento do } \\
\text { que se chama } \\
\text { psicopatologia } \\
\text { fenomenológica }\end{array}$ & $\begin{array}{l}\text { Revista da } \\
\text { Abordagem } \\
\text { Gestáltica } \\
\text { Phenomenological } \\
\text { Studies }\end{array}$ & 2015 \\
\hline $\begin{array}{l}\text { 28. Leite, M. E., \& } \\
\text { Moreira, V. }\end{array}$ & $\begin{array}{l}\text { A contribuição de } \\
\text { Tellenbach e Tatossian } \\
\text { para uma compreensão } \\
\text { fenomenológica da } \\
\text { depressão }\end{array}$ & $\begin{array}{l}\text { Arquivos Brasileiros } \\
\text { de Psicologia }\end{array}$ & 2009 \\
\hline 29. López-Silva, P. & $\begin{array}{l}\text { Consideraciones críticas } \\
\text { sobre la propuesta de } \\
\text { Thomas Szasz. Entre } \\
\text { filosofía de la mente, } \\
\text { fenomenología } \\
\text { psiquiatría }\end{array}$ & $\begin{array}{l}\text { Revista } \\
\text { Latinoamericana de } \\
\text { Psicopatologia } \\
\text { Fundamental }\end{array}$ & 2014 \\
\hline 30. Manganaro, $\mathrm{P}$. & $\begin{array}{l}\text { A psiquiatria } \\
\text { fenomenológico- } \\
\text { existencial na Itália }\end{array}$ & Memorandum & 2006 \\
\hline $\begin{array}{l}\text { 31. Mano, R. P., \& } \\
\text { Costa, I. I. }\end{array}$ & $\begin{array}{l}\text { "Deus não morreu e o } \\
\text { diabo existe": reflexões } \\
\text { fenomenológicas sobre a } \\
\text { experiência espiritual e o } \\
\text { sofrimento psíquico } \\
\text { grave }\end{array}$ & $\begin{array}{l}\text { Revista } \\
\text { Abordagem } \\
\text { Gestáltica }\end{array}$ & 2015 \\
\hline $\begin{array}{l}\text { 32. Martins, F. M. D. } \\
\text { M. C. }\end{array}$ & $\begin{array}{l}\text { Esquema da coisa (das } \\
\text { Ding) de Husserl e a } \\
\text { Esquizofrenia. }\end{array}$ & $\begin{array}{l}\text { Revista da } \\
\text { Abordagem } \\
\text { Gestáltica }\end{array}$ & 2009 \\
\hline
\end{tabular}




\begin{tabular}{|c|c|c|c|}
\hline $\begin{array}{l}\text { 33. Melo, A. K. S. \& } \\
\text { Moreira, V. }\end{array}$ & $\begin{array}{l}\text { Fenomenologia da } \\
\text { queixa depressiva em } \\
\text { adolescentes: um estudo } \\
\text { crítico-cultural. }\end{array}$ & Aletheia & 2008 \\
\hline $\begin{array}{l}\text { 34. Melo, A. K. S., } \\
\text { Boris, G. D. J. B., \& } \\
\text { Stoltenborg, V. }\end{array}$ & $\begin{array}{l}\text { Reconstruindo sentidos } \\
\text { na interface de histórias: } \\
\text { uma discussão } \\
\text { fenomenológico- } \\
\text { existencial da } \\
\text { constituição do sujeito } \\
\text { borderline }\end{array}$ & $\begin{array}{l}\text { Revista da } \\
\text { Abordagem } \\
\text { Gestáltica }\end{array}$ & 2009 \\
\hline $\begin{array}{l}\text { 35. } \quad \text { Meyer, L. F., } \\
\text { Taborda, J. G. V., } \\
\text { Costa, F. A., Soares, A. } \\
\text { L. A. G., Mecler, K., } \\
\text { Valença, A. L. }\end{array}$ & $\begin{array}{l}\text { Phenomenological } \\
\text { aspects of the cognitive } \\
\text { rumination construct }\end{array}$ & $\begin{array}{l}\text { Trends in Psychiatry } \\
\text { and Psycotherapy }\end{array}$ & 2015 \\
\hline 36. Moreira, V. & $\begin{array}{l}\text { O método } \\
\text { fenomenológico de } \\
\text { Merleau-Ponty como } \\
\text { ferramenta crítica na } \\
\text { pesquisa em psicologia }\end{array}$ & $\begin{array}{l}\text { Psicologia: Reflexão } \\
\text { e Crítica }\end{array}$ & 2004 \\
\hline $\begin{array}{l}\text { 37. Moreira, V., Cruz, } \\
\text { A. V. H., \& } \\
\text { Vasconcelos, L. B. }\end{array}$ & $\begin{array}{l}\text { O caso Ellen West de } \\
\text { Binswanger: } \\
\text { fenomenologia clínica de } \\
\text { uma existência } \\
\text { inautêntica }\end{array}$ & $\begin{array}{l}\text { Revista Mal-Estar e } \\
\text { Subjetividade }\end{array}$ & 2005 \\
\hline $\begin{array}{l}\text { 38. } \quad \text { Moreira, V., \& } \\
\text { Cavalcante Junior, F. S. }\end{array}$ & 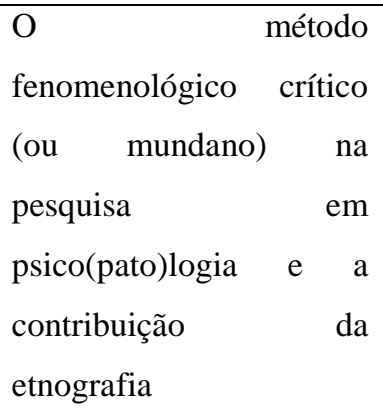 & $\begin{array}{l}\text { Estudos e Pesquisas } \\
\text { em Psicologia }\end{array}$ & 2008 \\
\hline $\begin{array}{l}\text { 39. Moreira, V., } \\
\text { Mesquita, S., \& Melo, } \\
\text { A. K. }\end{array}$ & $\begin{array}{l}\text { A experiência de } \\
\text { hospitalização vivida por } \\
\text { pacientes com AIDS }\end{array}$ & Boletim de Psicologia & 2010 \\
\hline
\end{tabular}




\begin{tabular}{|c|c|c|c|}
\hline 40. $\quad$ Moreira, V. & $\begin{array}{l}\text { A contribuição de } \\
\text { Jaspers, Binswanger, } \\
\text { Boss e Tatossian para a } \\
\text { psicopatologia } \\
\text { fenomenológica }\end{array}$ & $\begin{array}{l}\text { Revista da } \\
\text { Abordagem } \\
\text { Gestáltica }\end{array}$ & 2011 \\
\hline $\begin{array}{l}\text { 41. Moreira, V., \& } \\
\text { Bloc, L. }\end{array}$ & $\begin{array}{l}\text { Fenomenologia do tempo } \\
\text { vivido no transtorno } \\
\text { bipolar }\end{array}$ & $\begin{array}{l}\text { Psicologia: Teoria e } \\
\text { Pesquisa }\end{array}$ & 2012 \\
\hline 42. Moreira, V. & $\begin{array}{l}\text { From essence to } \\
\text { Lebenswelt as a method } \\
\text { in phenomenological } \\
\text { psychopathology }\end{array}$ & $\begin{array}{l}\text { Estudos de Psicologia } \\
\text { (Campinas) }\end{array}$ & 2016 \\
\hline $\begin{array}{c}\text { 43. Peixoto, M. M., } \\
\text { Mourão, A. C. N., \& } \\
\text { Serpa Junior, O. D. }\end{array}$ & $\begin{array}{l}\text { O encontro com a } \\
\text { perspectiva do outro: } \\
\text { empatia na relação entre } \\
\text { psiquiatras e pessoas } \\
\text { com diagnóstico de } \\
\text { esquizofrenia }\end{array}$ & $\begin{array}{l}\text { Ciência e Saúde } \\
\text { Coletiva }\end{array}$ & 2016 \\
\hline $\begin{array}{l}\text { 44. Pita, J., \& } \\
\text { Moreira, V. }\end{array}$ & $\begin{array}{l}\text { As fases do pensamento } \\
\text { fenomenológico de } \\
\text { Ludwig Binswanger }\end{array}$ & Psicologia em Estudo & 2013 \\
\hline $\begin{array}{l}\text { 45. Rocha, M. A. S. } \\
\text { D., Boris, G. D. J. B., } \\
\text { \& Moreira, V. }\end{array}$ & $\begin{array}{l}\text { A experiência suicida } \\
\text { numa perspectiva } \\
\text { humanista- } \\
\text { fenomenológica }\end{array}$ & $\begin{array}{l}\text { Revista da } \\
\text { Abordagem } \\
\text { Gestáltica }\end{array}$ & 2012 \\
\hline 46. $\quad$ Rovaletti, M. L. & $\begin{array}{l}\text { Alcance y } \text { significación } \\
\text { da psico(pato)logía } \\
\text { fenomenológica }\end{array}$ & $\begin{array}{l}\text { Revista } \\
\text { Abordagem } \\
\text { Gestáltica }\end{array}$ & 2015 \\
\hline 47. Santos, G. A. O. & $\begin{array}{l}\text { A angústia e a culpa no } \\
\text { transtorno obsessivo- } \\
\text { compulsivo: uma } \\
\text { compreensão } \\
\text { fenomenológico- } \\
\text { existencial }\end{array}$ & $\begin{array}{l}\text { Revista } \\
\text { Abordagem } \\
\text { Gestáltica }\end{array}$ & 2013 \\
\hline 48. Santos, G. A. O. & $\begin{array}{l}\text { Contribuições da obra de } \\
\text { Luis Marti-Santos para a } \\
\text { psicoterapia }\end{array}$ & Revista do NUFEN & 2013 \\
\hline
\end{tabular}




\begin{tabular}{|c|c|c|c|}
\hline $\begin{array}{l}\text { 49. Santos Filho, J. } \\
\text { M. \& Costa, V. E. S. } \\
\text { M. }\end{array}$ & $\begin{array}{l}\text { Encontrando um modo } \\
\text { de ser esquizofrênico: } \\
\text { arte e técnica na gestalt- } \\
\text { terapia }\end{array}$ & $\begin{array}{l}\text { Revista da } \\
\text { Abordagem } \\
\text { Gestáltica }\end{array}$ & 2016 \\
\hline $\begin{array}{l}\text { 50. Schleder, K. S. \& } \\
\text { Holanda, A. F. }\end{array}$ & $\begin{array}{l}\text { Nise da Silveira e o } \\
\text { enfoque fenomenológico }\end{array}$ & $\begin{array}{l}\text { Revista da } \\
\text { Abordagem } \\
\text { Gestáltica }\end{array}$ & 2015 \\
\hline $\begin{array}{l}\text { 51. } \quad \text { Serpa Junior, O. } \\
\text { D., Leal, E. M., } \\
\text { Louzada, R. D. C. R., } \\
\text { \& Silva Filho, J. F. }\end{array}$ & $\begin{array}{l}\text { A inclusão da } \\
\text { subjetividade no ensino } \\
\text { da Psicopatologia }\end{array}$ & $\begin{array}{l}\text { Interface } \\
\text { Comunicação, Saúde } \\
\text { e Educação }\end{array}$ & 2007 \\
\hline $\begin{array}{l}\text { 52. } \quad \text { Silva, N. H. L. P., } \\
\text { \& Cardoso, C. L. }\end{array}$ & $\begin{array}{l}\text { Contribuições da } \\
\text { fenomenologia de Edith } \\
\text { Stein para a atuação do } \\
\text { psicólogo nos Núcleos de } \\
\text { Apoio à Saúde da } \\
\text { Família (NASF). }\end{array}$ & $\begin{array}{l}\text { Revista } \\
\text { Latinoamericana de } \\
\text { Psicopatologia } \\
\text { Fundamental }\end{array}$ & 2013 \\
\hline $\begin{array}{l}\text { 53. } \\
\text { Merlo, A. R. C. }\end{array}$ & $\begin{array}{l}\text { O medo: expressão de } \\
\text { um coletivo de } \\
\text { trabalhadores }\end{array}$ & $\begin{array}{l}\text { Fractal: Revista de } \\
\text { Psicologia }\end{array}$ & 2014 \\
\hline $\begin{array}{l}\text { 54. Souza, C. P. D., } \\
\text { Callou, V. T., \& } \\
\text { Moreira, V. }\end{array}$ & $\begin{array}{ll}\text { A questão } & \text { da } \\
\text { psicopatologia } & \text { na } \\
\text { perspectiva } & \text { da } \\
\text { abordagem centrada na } & \\
\text { pessoa: diálogos com } \\
\text { Arthur Tatossian }\end{array}$ & $\begin{array}{l}\text { Revista da } \\
\text { Abordagem } \\
\text { Gestáltica }\end{array}$ & 2013 \\
\hline $\begin{array}{l}\text { 55. Souza Júnior, N. } \\
\text { J. }\end{array}$ & $\begin{array}{l}\text { Analítica do dasein e } \\
\text { daseinsanalyse }\end{array}$ & Revista do NUFEN & 2009 \\
\hline $\begin{array}{l}\text { 56. } \text { Spohr, B., \& } \\
\text { Schneider, D. R. }\end{array}$ & $\begin{array}{l}\text { Bases epistemológicas da } \\
\text { antipsiquiatria: } \\
\text { influência do } \\
\text { Existencialismo de Sartre }\end{array}$ & $\begin{array}{l}\text { Revista } \\
\text { Abordagem } \\
\text { Gestáltica }\end{array}$ & 2009 \\
\hline $\begin{array}{l}\text { 57. Telles, T. C. B., \& } \\
\text { Moreira, V. }\end{array}$ & $\begin{array}{l}\text { A lente fenomenológica } \\
\text { de Merleau-Ponty para a } \\
\text { Psicopatologia } \\
\text { Fundamental }\end{array}$ & $\begin{array}{l}\text { Psicologia: Teoria e } \\
\text { Pesquisa }\end{array}$ & 2014 \\
\hline
\end{tabular}




\begin{tabular}{|c|l|l|l|c|}
\hline $58 . \quad$ Tenório, C. M. D. & $\begin{array}{l}\text { As psicopatologias como } \\
\text { distúrbios das funções do } \\
\text { self: uma construção } \\
\text { teórica na abordagem } \\
\text { gestáltica }\end{array}$ & Abordagem & Gestáltica \\
& $\begin{array}{l}\text { Algumas considerações } \\
\text { sobre psicopatologia na } \\
\text { filosofia de Merleau- } \\
\text { Ponty }\end{array}$ & Ágora: Estudos em & Teoria Psicanalítica \\
\hline Furlan, R. & Vieira, M. G., \& & & \\
\hline
\end{tabular}

